\title{
A luz da beleza: a doutrina de Leon Battista Alberti por Andrea Loewen ${ }^{1}$ \\ Rodrigo de Almeida Bastos ${ }^{2}$
}

\begin{abstract}
1 Versão em espanhol publicada originalmente na sessão de recensioni de ALBERTIANA; Societé Internationale Leon Battista Alberti. Firenze: Leo S. Olschki Ed., vol. XVIII, 2015, pp. 311-5, sobre a obra de LOEWEN, Andrea. Lux Pulchritudinis: sobre beleza e ornamento em Leon Battista Alberti. São Paulo: Annablume, 2012.

2 Rodrigo Bastos é arquiteto urbanista e engenheiro civil, mestre em arquitetura pela UFMG, doutor em Arquitetura pela USP. Foi professor adjunto da Escola de Arquitetura da UFMG e desde 2011 é professor do Departamento de Arquitetura e Urbanismo da UFSC. Possui linhas de pesquisa em teoria e história da arquitetura e do urbanismo no Brasil, em Estética da Arquitetura e em Teoria de projeto. É autor de $A$ maravilhosa fábrica de virtudes e $A$ arte do urbanismo conveniente.
\end{abstract}

3 VALÉRY, Paul. Leçon inaugurale du Cours de Poétique du Collège de France, in Variété $\mathrm{V}$, Nrf, Gallimard, 1944, pp. 295-322. Disponível em: (http://classiques.uqac. $\mathrm{ca} /$ classiques/Valery_paul/varietes/Lecon_1_esthetique_Var_V/ cours de_poetique.pdf). Acesso: 20/11/2013. Cf. a edição brasileira, in: VALÉRY, Paul. Variedades. Trad. Maiza Martins de Siqueira. São Paulo: Iluminuras, 2012, pp. 179-192.

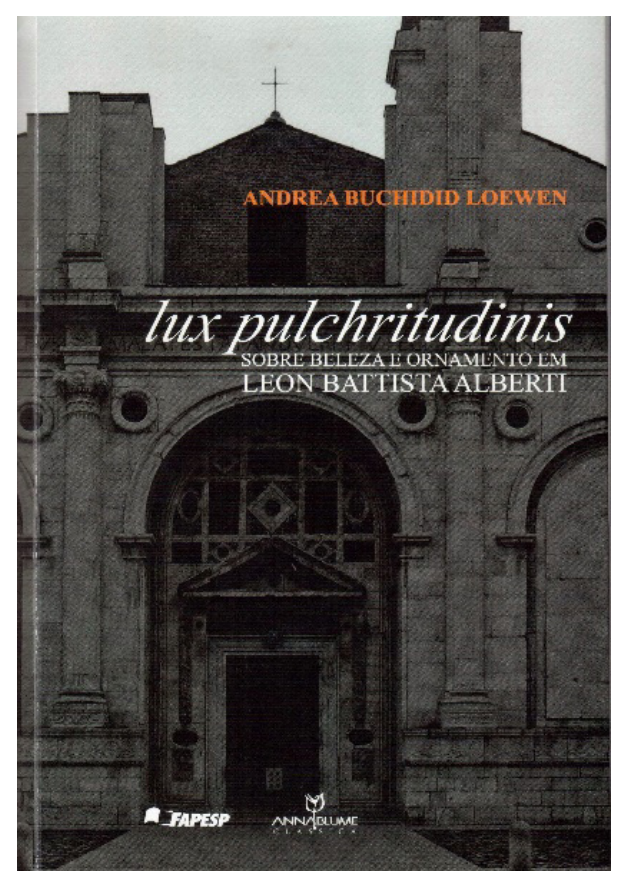

$\mathbf{N}$ o encerramento da Primeira aula do Curso de Poética - conferência inaugural proferida em 10 de dezembro de 1937 no Collège de France -, Paul Valéry parafraseou a máxima de Protágoras. Modificou-a, porém, tão sutilmente quanto radical pudesse ser: "Je m'efforce de n'oublier jamais que chacun est la mesure des choses" ${ }^{\prime 3}$. Valéry não mencionou a citação antiga: "O homem é a medida de todas as coisas", consciente de que sua audiência reconheceria a referência antiga; consciente também, podemos supor, que terminar a sua fala com aquela sentença propiciaria aos presentes um silêncio retumbante das reflexões assim evocadas.

Apesar da semelhança aparente dos enunciados, a forma mentis da modernidade de Valéry é bem distante, e bem distinta, daquela de Protágoras. Arrisco dizer que, no campo das artes, é praticamente outro mundo. Recorrendo ao dito antigo, a sutileza de Valéry está em resguardar um humanismo essencial sob outra perspectiva, e por isso o poeta salienta, em seu discurso, o que agora está "em causa", em plena modernidade do século XX: interessa indagar, acima de tudo, o "espírito criador", circunstanciado na atenta "observação" das coisas por que passa "cada um" em sua experiência humana.

A geometria universal do homem foi substituída pela proporção relativa à experiência. A redução à "medi- 
da" humana radica, agora, no âmbito da subjetividade, e medra outra natureza - não mais mimética, mas estética. A "medida das coisas", então, é para Valéry uma analogia poética possível a partir da experiência humana; não mais nos moldes de uma materialidade exemplar tomada como modelo de beleza e ordenação do mundo, mas sim como tropo ou ornato eloquente que remete substancialmente à sensibilidade única, e inalienável, do sujeito moderno na "produção" das "obras do espírito". As proporções humanas não constituem mais um fundamento de doutrina, como o seria para todo o mundo antigo até pelo menos a primeira metade do século XVIII, passando e sendo revigoradas, essencialmente, por Alberti, mas uma referência poética capaz de remeter a uma subjetividade moderna que, por assim dizer, desterrou a beleza dos objetos situando-a no âmago do espírito humano; não mais nas relações de proporções com que a alma poderia vislumbrar a beleza das matérias, superfícies e corpos entre si e com o todo, mas na qualidade fecunda, e imprevisível, das sensações, percepções e pensamentos que se formam na consciência do espírito.

Cumpre distinguir o "espírito" de que fala Valéry (ele o usa também em Eupalinos e em Introdução ao Método de Leonardo da Vinci) da "alma" de que fala Alberti, em tantos de seus textos. Para este, é através da alma que o homem pode discernir o que é a beleza nos corpos e na natureza: é o sensu animis innato que permite ao homem o reconhecimento da concinnitas. Por isso, defenderá Alberti, a arte se ensina racionalmente, através de regras e preceitos, e elas assimilam o costume como mandamento, correção de proporções e tópoi que comprovaram o seu valor, a sua eficácia, consagrando-se no aplauso discreto podendo chegar a se tornar autoridade. A "novidade" não era, como no tempo pós-iluminista que perpassa Valéry, uma originalidade inédita alcançada pelo espírito genial, mas um resultado agudo do engenho que imita além da mera cópia; que emula, adiciona, subtrai ou transforma as matérias ou formas conhecidas em adequação maravilhosa às circunstâncias de gênero, lugar, finalidade e recepção.

Súmula do mundo antigo, a tópica do corpo belo, comedido e ordenado - a um só tempo admirável e útil - é fundamental para se compreender o pensamento de Alberti. E é Leon Battista quem proporciona as principais e mais influentes doutrinas modernas, quer sobre a beleza, quer sobre o ornamento. Malgrado o percurso crítico desses dois conceitos no último século - quando um foi criminalizado e a outra, a pouco 
${ }^{4}$ Cf. LOEWEN, Andrea Buchidid. Lux pulchritudinis: sobre beleza e ornamento em Leon Battista Alberti. São Paulo: Annablume, 2012, p. 37.

5 LOEWEN, op. cit., p. 17.

${ }^{6}$ LOEWEN, op. cit., p. 156. e pouco, questionada e praticamente alijada dos interesses da arte moderna ou dita de vanguarda - , ornamento e beleza proporcionam fundamentos incontornáveis para uma judiciosa apreciação da história da arte.

Enuncia Alberti: a beleza é uma "precisa relação de concinnitas (simetria) das partes no todo, de modo que não se possa acrescentar ou subtrair ou mudar nada, sem que o torne reprovado" ${ }^{4}$. Nesta passagem, a tradução de Andrea Loewen reconstitui a symmetria antiga como relação proporcional das partes e do todo, concitando o leitor também a reconhecer a decisiva filiação poético-retórica que anima Alberti filiação esta que será decisiva para a tese presente em Lux pulchritudinis. O ornamento é uma sorte de luz aderente, complementar ou auxiliar, acrescentada àquela beleza inerente aos corpos de modo a fazê-la neles rebrilhar com esplendor, ou a remediar-Ihes alguma imperfeição.

Quão simples as definições de Alberti. A ratio mediocritas que orienta o estilo é conveniente e confere uma clareza luminar aos tratados. Percorrendo também as suas fontes, confrontadas à extensão, em todo o livro, Andrea Loewen evidencia os preceitos, os tópoi e os exempla com que Alberti desenvolve e autoriza suas doutrinas, adaptando-as às artes da pintura, da escultura e da arquitetura:

Dos nexos entre a Retórica e as artes figurativas, das relações entre estas e as ciências matemáticas, dos consórcios com os escritos antigos, Leon Battista compõe sua doutrina do belo. Recolhendo os veneráveis saberes, sistematizando-os e adicionando suas próprias perquirições, ele monta seu discurso, unificando e redefinindo noções para então distribuí-las com conveniência e colocá-las de maneira precisa e oportuna em meio à policromia lexical que conforma e luz sua preceptiva ${ }^{5}$.

Loewen recorda a imagem albertiana do "mosaico"6 e faz dela uma chave para se compreender a vária fundação albertiana, uma composição que assimila engenhosamente os vetustos (Cícero, Quintiliano, Vitrúvio, Euclides, Plínio, Horácio), os monumentos romanos e a "novidade" dos artistas florentinos de seu tempo, como Filippo, Donatello e Ghiberti.

A concinnitas - "primeira regra da natureza" - é o núcleo musical primordial com que sistematizar a pulcritude visual, a harmonia, o ritmo e a eloquência requerida nos discursos e na arquitetura: "aqueles números que dão aos sons a concinnitas, gratíssima aos ouvidos, são os mesmos que enchem os olhos e a 
alma de admirável satisfação"7. Mas o arsenal de conceitos e preceitos que revestem o corpus doutrinário é imenso, e riquíssimo, irredutível a essa ou aquela lei, no que são reanimados, então, durante todo o livro, para revivescer a pedagogia albertiana.

Consonante ao decoro da retórica textual do humanista, Andrea edifica o corpo do livro. Lux pulchritudinis se organiza, então, como um corpo coeso, integral em sua perfeição. Inicia o livro problematizando a optima doctrina albertiana, com o que, depois, analisa, em capítulos seguintes, a discussão de tópicas essenciais do corpus albertiano: a pulchritudo e o ornatus retórico-arquitetônico, a concinnitas, a doutrina da imitação, a lei suprema do decoro. Erguidas essas partes essenciais do edifício doutrinário, a seguir espelha-o, finalmente, nos edifícios mesmos, inventados ou reformados por Alberti: em Rimini, em Mântua, em Florença, destacando o entendimento "da beleza como fato ético e da Arquitetura como instrumento de bom governo" $^{\prime 8}$. Reconstituindo sua retórica arquitetural à maneira de exempla ideados e edificados, Loewen supera as dicotomias modernas entre teoria e práxis, forma e conteúdo, forma e função, estranhas ao regime poético de Alberti, e também as advertências históricas que problematizam a correspondência absoluta entre regras e edifícios. Reconstruindo arqueologicamente a sua retórica, sobretudo com Cícero e Quintiliano, Loewen desvela a luminosidade das doutrinas que fazem refulgir a lux pulchritudinis albertiana e atualiza a máxima de Horácio refluindo finalmente a arquitetura em meio ao paragone das artes - ut rethorica arquitectura. Na proficuidade de seu método e de suas hipóteses, termina por demonstrar que as histórias da arte e da arquitetura se beneficiam bastante com uma reconstituição precisa das preceptivas coevas às obras analisadas. Evitando, assim, anacronismos que pudessem comprometer a arqueologia dos conceitos albertianos, reconstitui não apenas a materialidade dos preceitos, porquanto contribui decisivamente para evidenciar-lhes a devida importância histórica. A lição há que se compreender extensa a toda historiografia da arte.

Todas as partes convêm à discussão da beleza e do ornamento, o que ofereceria muitas armadilhas ao investigador. A noção de beleza, assim como exposta por Wittkower, por exemplo, determina um protagonismo racional do belo sob aquele modelo matemático do corpo, salienta Loewen ${ }^{9}$. Mas a compreensão albertiana do decoro, vigorada pelas menções à preceptiva poético-retórica antiga, relativiza a positividade absoluta do numerus, compreendendo-o integrado a
7 ALBERTI apud LOEWEN, op. cit., p. 65.

8 LOEWEN, op. cit., p. 154.

9 LOEWEN, op. cit., p. 53-5. 
10 LOEWEN, op. cit., p. 145.

11 SOLÁ-MORALES, Ignasí de. Diferencias: topografía de la arquitectura contemporánea. Barcelona, Gustavo Gili, 2003.

12 LOEWEN, op. cit., p. 25;36. vários outros conceitos. Assim, a lei suprema da conveniência humaniza, por assim dizer, a medida, o ritmo, moldando-os em adequação ao corpo mesmo, na conveniência ética com que se devem perfazer todas as ações e produções humanas, na conveniência patética com que os movimentos do corpo se conformam aos movimentos da alma.

É sob esse lastro fundamental do decoro que se exalça também - a uma posição cumular na doutrina albertiana - o ornamento. Tido como acrescentado - e muitas foram as compreensões, na história, que o trataram como acessório supérfluo ou dispensável, sobretudo a partir da crítica moderna aos catálogos de ornatos que se multiplicaram no século XIX, culminando com a severa delação de Adolf Loos - , sob o registro do decoro, o ornamento assume elevada importância, conquanto nunca desmedido, a conferir justeza, dignidade e representação evidentes da razão de ser do edifício e da cidade. Assim é que Andrea pode ultimar a discussão do decoro, no capítulo IV:

Desse modo, respondendo à necessidade e satisfazendo o deleite, o ornamento supera a esfera do acessório, se redime de seu valor meramente decorativo e, impregnado de significado ético, passa a ser visto como elemento essencial e identificado com a própria beleza ${ }^{10}$.

Para além do necessário sentido histórico da investigação, há que se lembrar também daquele chamamento ético que fez Ignasí de Solà-Morales em seu livro Diferencias: topografía de la arquitectura contemporánea, publicado originalmente em $1996^{11}$. Analisando o que ele chamou de "essência decorativa da arquitetura", à luz de pensadores como Goethe, Heidegger, Vattimo e Gadamer, o teórico da arquitetura espanhol defendeu a tese de que deveríamos voltar a indagar o sentido essencial que teve a palavra "decorum" na história da arquitetura. Essa investigação poderia revelar não apenas o significado de conceitos como o decoro, a beleza e o ornamento, mas também o sentido poético da própria arquitetura, inclusive nos dias atuais.

A doutrina da beleza surge no De pictura, adquirindo contornos mais precisos no De re aedificatoria, demonstra Loewen ${ }^{12}$. Os dois tratados sinalizam momentos fundamentais na constituição do pensamento albertiano, formado também por outros textos de variados gêneros, que a pesquisadora igualmente visita e faz dialogar oportunamente com os tratados. E são várias as sinonímias da beleza: pulchritudo, uenustas, decoris, leporis, formosum, gratia, amœnitas, concinnitas, ornamentum, guardando filigranas de sentido 
que se iluminam à medida que a pesquisadora examina as fontes do humanista. A metáfora do ornamento como luz encontra-se nos tratados antigos de retórica ${ }^{13}$. Desta feita, como um belo ornamento de caráter ciceroneano, acrescentado e intrínseco a uma inumerável coleção de estudos sérios e relevantes, Lux pulchritudinis contribui decisivamente para o desvelamento da estrutura digníssima do pensamento de Leon Battista Alberti.

\section{Referências}

ALBERTIANA; Societé Internationale Leon Battista Alberti. Firenze: Leo S. Olschki Ed., vol. XVIII, 2015.

LOEWEN, Andrea. Lux Pulchritudinis: sobre beleza e ornamento em Leon Battista Alberti. São Paulo: Annablume, 2012.

SOLÁ-MORALES, Ignasí de. Diferencias: topografía de la arquitectura contemporánea. Barcelona, Gustavo Gili, 2003.

VALÉRY, Paul. Leçon inaugurale du Cours de Poétique du Collège de France, in Variété $V$, Nrf, Gallimard, 1944, pp. 295-322. Disponível em: (http://classiques.uqac.ca/classiques/ Valery_paul/varietes/Lecon_1_esthetique_Var_V/cours_de_poetique.pdf).

VALÉRY, Paul. Primeira aula do curso de poética. In: VALÉRY, Paul. Variedades. Trad. Maiza Martins de Siqueira. São Paulo: Iluminuras, 2012., pp. 179-192. 